\title{
Impact of Educational Intervention for Improving Pharmacist Knowledge in Adverse Drug Reactions (ADR) Reporting: Experience from Malaysia
}

\author{
Ramadan Mohamed Elkalmi*,1, Mohamed Azmi Hassali ${ }^{1}$, Mohamed Izham M. Ibrahim² \\ ${ }^{I}$ Discipline of Social and Administrative Pharmacy, School of Pharmaceutical Sciences, Universiti Sains Malaysia, \\ Penang, Malaysia; '2Pharmacy Practice Department, College Of Pharmacy, Al Qassim University, Buraidah, \\ Saudi Arabia
}

\begin{abstract}
Background: Community Pharmacists are one of healthcare professionals who can play an important role in the reporting of Adverse Drug Reactions (ADRs) due to the advantageous position in terms of direct contact with the patients and specialization in medicine. Nevertheless, literatures indicated that ADRs under-reporting are common among community pharmacists in both developed and developing countries.

Objectives: To assess the knowledge and perception of community pharmacists in Malaysia towards the reporting of ADRs and to evaluate the effectiveness of an educational program for improving pharmacist knowledge in ADRs reporting.

Methods: A cross-sectional study employing pre and post intervention design was undertaken with a sample of 42 community pharmacists. Changes in scores before and after the completion of the training program in knowledge and perception were measured. Statistical analysis: The data were analyzed by using SPSS version 17.0 software package (SPSS Inc., Chicago, IL, USA). Both descriptive and inferential statistics were used when ever appropriate. Frequencies and percentages were used to describe the respondents' demographic information and professional characteristics. Wilcoxon Signed ranks test, Paired sample t test and The McNemar $\chi 2$ test were applied to compare the differences in knowledge and perception before and after the educational program whenever appropriate.
\end{abstract}

Results: Forty-two community pharmacists (CPs) were enrolled in this study. A comparison of CPs knowledge before and immediately after the implementation of the education program showed significant differences. The participating CPs' mean + SD total scores in the knowledge of pharmacovigilance and ADRs reporting significantly increased compared to the baseline following the intervention $4.6 \pm 1.9$ to $8.3 \pm 1.4(\mathrm{p}<0.001)$, the possible score in knowledge domain ranged from zero to10. Only a few $(n=3,7 \%)$ participants reported that they do not have any ideas of how to report ADR to the relevant authorities in Malaysia compared to pre-intervention case $(\mathbf{n}=\mathbf{2 2}, \mathbf{5 0} \%)$. Upon completion of the education program, more than forty of the respondents $(n=19,45 \%)$ believed that they were confident of their knowledge in detection and performing ADRs reporting, in contrast with pre-intervention frequencies, slightly more than fifty percent of the participants agreed that their knowledge in ADR limit their ability to detect and report of ADRs (n= 32, 55\%), $(\mathrm{N}=42, \mathrm{P}=0.004)$.

Conclusion: The finding of the study indicates the need for designing educational programs for community pharmacists, in order to improve the level of knowledge towards the pharmacovigilance and ADRs reporting process locally.

Keywords: Pharmacovigilance, adverse drug reaction reporting, community pharmacists, educational program, Malaysia.

\section{INTRODUCTION}

In Malaysia, a system for the spontaneous reporting of suspected ADRs has now been operating for more than 25 years. The Malaysian Adverse Drug Reaction Advisory Committee (MADRAC) is responsible for collecting and analyzing ADR reports on behalf of the Drug Control Authority (DCA). Reports of suspected ADRs are submitted voluntarily by health care professionals including community pharmacists (CPs) as well as from the pharmaceutical

*Address correspondence to this author at the Discipline of Social and Administrative Pharmacy, School of Pharmaceutical Sciences, Universiti Sains Malaysia,11800, Minden Pinang, Malaysia; Tel: +60 (0)4 657 0017; Fax: +60 (0)4 653 4055; E-mail: edriph@gmail.com industry and registration holders whereby they are obligated by the law to report suspected ADRs. Community pharmacists were requested to report suspected ADRs in accordance with the Malaysian ADRs reporting guidelines [1]. Improving the level of awareness and knowledge of the community pharmacists to the importance of ADRS reporting and the methods of reporting are usually reflected positively in the quality and the rate of reporting. This can be achieved by specific education and training program focused on ADR reporting [2].

\section{STUDY OBJECTIVES}

This study aimed to assess the knowledge and perception of community pharmacists in Malaysia towards the reporting of adverse drug reactions (ADRs) and to evaluate the effec- 
tiveness of an educational program for improving pharmacist knowledge in ADRs reporting.

\section{METHODS}

\section{Study Population and Setting}

This study was undertaken in the state of Penang, Malaysia. All community pharmacists registered in the state of Penang Malaysia were invited via mail to participate in a half day educational seminar on pharmacovigilance and ADRs reporting process.

\section{Study Design}

This study was a pretest-posttest (before-after) survey of a single group (Fig. 1). The content of the educational session was prepared by the expertise from the school of pharmacy and was delivered via expertise in the field of pharmacovigilance. Pre-evaluation questionnaire was given in order to get the baseline knowledge of the pharmacists. Impact of the educational program: a post educational intervention assessment was conducted aiming to evaluate the knowledge of and perception of the community pharmacists towards ADRs reporting following the completion of the program. From around 210 community pharmacists registered as community pharmacist in Penang state, only 42 community pharmacists $(20 \%)$ agreed to participate in this educational program.

\section{Description of the Educational Program on Pharma- covigilance and ADR Reporting}

The educational program was designed for community pharmacists; the content of the educational materials was customized to include issues on pharmacovigilance and ADR reporting in the community settings. The materials were delivered through didactic lectures, demonstrations, and interactive discussions. The participants were expected to gain knowledge and take initiative in the pharmacovigilance activities and ADR reporting process. The course was aimed to provide participants with the knowledge of pharmacovigilance concept and the necessary skills to report ADRs. The key learning outcomes of the course included: understanding the epidemics of ADRs and the role of Pharmacoepidemiology in Drug Safety, highlighting the concept of pharmacovigilance, Pharmacist's role in ADRs Monitoring and Reporting: Current Scenario in Malaysia and Importance of ADR Reporting by community pharmacists.

\section{Instrument Development}

To achieve the goal of the study, a new questionnaire was developed; the questionnaire covering the following areas: (I) personal and professional information (12 questions), (II) professional skills related to the Malaysian ADR spontaneous reporting system (5 questions), (III) basic knowledge about ADR reporting and the importance of pharmacovigilance (10 questions), (IV) beliefs and perceptions linked to spontaneous ADRs reporting (6 questions).

\section{Data Collection}

The educational program about pharmacovigilance and ADR reporting was developed and delivered to the pharmacists who were practicing as community pharmacist in Penang and who planned to attend this educational training program upon invitation from the Malaysian Pharmaceutical Society (MPS). A pre-test and post-test survey of a single group was conducted and the differences in the scores on knowledge and perception of the community pharmacists before and after the training program were measured. Ethical approval for the study was guarantied from the MPS and the Discipline of Social and Administrative Pharmacy (DSAP) at the School of Pharmaceutical Sciences, Universiti Sains Malaysia (USM). All protocols and materials used in the study were developed by the authors, 2 of them had considerable experience in pharmacy practice research, and 1 who was a PhD. candidate. Each participant was given a certificate of attendance. Malaysian Pharmaceutical Society (MPS) adopted this study protocol as part of their Continuing Pharmaceutical Development (CPD) programs. None of the participants were compensated in any way for their time or involvement in the study.

\section{Study Place}

The evaluation session was held at the school of pharmaceutical sciences of Pharmacy, Universiti Sains Malaysia in April 2009. The workshops were planned over a half day and a seminar manual containing relevant material was prepared.

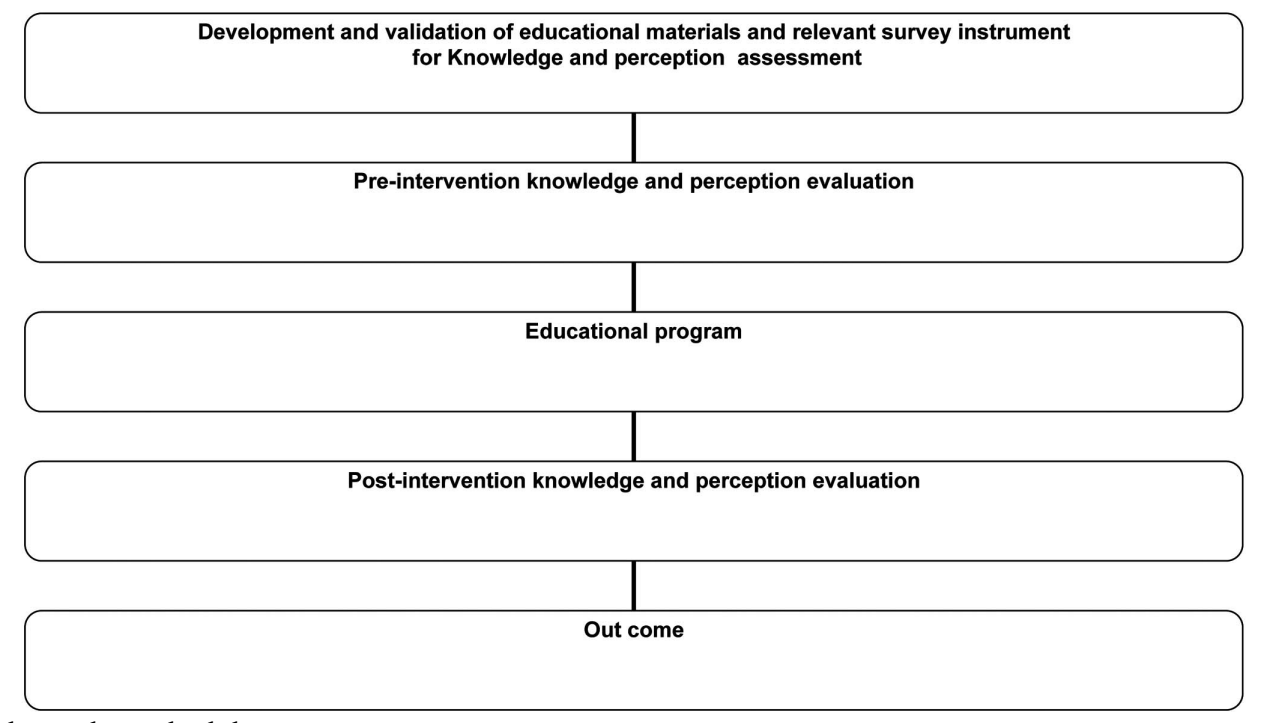

Fig (1). Flowchart of the study methodology. 
All the professionals who conducted the training worked in research and taught in institutions or had a training role in their professional bodies. All participants were asked to complete a questionnaire regarding the socio-demographics, knowledge of and perception about pharmacovigilance and ADRs reporting before and after the educational program.

\section{Statistical Analysis}

The data were analyzed by using SPSS version 17.0 software package (SPSS Inc., Chicago, IL, USA). Both descriptive and inferential statistics were used when ever appropriate. Frequencies and percentages were used to describe the respondents' demographic information and professional characteristics. Wilcoxon Signed ranks test, Paired sample t test and the McNemar $\chi 2$ test were applied to compare the differences in knowledge and perception before and after the educational program whenever appropriate. A $\boldsymbol{p}$-value of 0.05 or less was considered to be significant.

\section{RESULTS}

\section{Socio-Demographics Characteristics}

From around 210 community pharmacists registered as community pharmacist in Penang state, only 42 CPs $(20 \%)$ agreed to participate in this educational program. Altogether 42 community pharmacists gave their responses, about sixty percent $(n=24,57 \%)$ of them were female and $18(43 \%)$ were males. The mean age of the participants was $35 \pm 8.6$ years with a median of 33 years. Slightly more than onethird $(15,36 \%)$ of participants were within the age group of 25-29 years old. None of the participants had received any formal training on pharmacovigilance or ADR reporting procedures. All of the pharmacists $(100 \%)$ had a bachelor of pharmacy degree. About half of the participants $(n=22,52 \%)$ had worked less than five years as community pharmacists. Out of the 42 community pharmacists, only 9 pharmacists (21\%) were familiar with MADRAC (Table 1).

There was no Statistical significant difference regarding the knowledge about pharmacovigilance/ the practicing of ADR reporting in subgroups pertaining to age, gender, length of practicing, country of graduation, participation in continuous pharmaceutical development programs (CPD), and encountering ADRs during their practice. However, the study results showed that there was a significant difference between reporting of ADRs and familiarity with MADRAC $(P=0.025)$. Although, half of the respondents indicated that during one year before the study, they had come across ADRs, only $9 \%$ of the respondents claimed that they had submitted at least one ADR report to MADRAC. Despite around two-thirds $(n=31,74 \%)$ of the participants claimed they had access to the internet at their workplace, only 10 (23\%) pharmacists stated that they were aware of the possibility of submitting reports via the internet here in Malaysia.

\section{Changes in Scores of Knowledge Were Measured}

The knowledge of pharmacovigilance and ADRs reporting among the community pharmacists was assessed by asking 10 true /false questions. A score of 1 was given for each correct answer and 0 score for each wrong answer. The maximum score obtainable was 10 and a minimum of Zero. The community pharmacists' overall pretest and posttest scores were compared based on the number of questions answered correctly. The pre-assessments and postassessments were completed by all of the 42 CPs. The mean \pm SD total knowledge score of pharmacovigilance and ADRs reporting after the intervention significantly increased from 4.6 \pm 1.9 to $8.3 \pm 1.4(\mathrm{~N}=42, \mathrm{P}<001)$. In the pre-assessment: only $8(19 \%)$ pharmacists answered the question correctly regarding the need to make sure that the causality relationship between the drug and the ADR existed, and also 7 $(17 \%)$ of them responded correctly to a question linked to the reporting of ADRs associated with the use of herbal products and whether ADRs should be reported in such situation or not. In the post assessment, there was a tremendous improvement in the proportion of community pharmacists having correct responses to the items relating to the knowledge domain. There was a remarkable statistical significant difference between the responses to all questions relating to the knowledge domain before and after the educational program (Table 2). There was no significant difference regarding the knowledge about pharmacovigilance/ the practicing of $A D R$ reporting in subgroups pertaining to gender, age, country of graduation, and length of practicing $(P=0.734 ; P=0.463 ; P=0.437 \& P=0.976)$ respectively in the pre-assessment, while there was significant difference with age in the post assessment $(P=0.039)$, where majority $(n=13,88 \%)$ of the respondents aged $25-29$ reported that they didn't submit any ADRs report in the 12 months previous to conducting of this study.

The perception domain assessed the community pharmacist's perception towards the pharmacovigilance activities locally and the capability of community pharmacists to perform the ADRs reporting before and immediately following the educational program. This domain used a 5-point Likert scale for the pharmacists to rate their level of the agreement or disagreement with the domain items. To simplify the comparison, Likert scale responses for community pharmacist's perceptions were collapsed into three categories - scale responses of strongly disagree and disagree to signify disagreement, a scale response to signify neutral response; and a response of agreement or strong agreement to signify agreement with the perception question prior and following the educational intervention. Accordingly, median scores and percentages on the three answer categories were determined (Table 3).

Upon the completion of the educational program, the majority $(n=37,88 \%)$ of the participants expressed their disagreement with the statement that "I do not have any idea of how to report ADR to the relevant authorities in Malaysia" comparing to the pre -assessment $(n=22,50 \%)$. There was a significant difference between responses to this question in pre and post intervention $(P<0.001)$. Around two-thirds $(n=27,64 \%)$ of the community pharmacists perception changed towards encountering ADRs during their practice and they observed that it is not hard to observe ADRs during their daily duties. After the education program around twothirds of the pharmacists $(n=27,64 \%)$ observed that it was easy to detect ADRs during their practice $(\mathrm{N}=42, P=$ 0.026). Upon completion of the education program, a large proportion of the respondents $(n=19,45 \%)$ believed that they were confident of their knowledge in detection and performing ADRs reporting, in contrast with pre-intervention fre 
Table 1. Socio-Demographic Characteristics $(N=42)$

\begin{tabular}{|c|c|c|}
\hline Characteristics & Frequency & $(\%)$ \\
\hline \multicolumn{3}{|l|}{ Gender } \\
\hline Female & 24 & $(57.1)$ \\
\hline \multicolumn{3}{|l|}{ Age in years } \\
\hline $25-29$ & 15 & $(35.7)$ \\
\hline $30-34$ & 7 & $(16.7)$ \\
\hline $35-39$ & 11 & $(26.2)$ \\
\hline$>40$ & 8 & $(19.0)$ \\
\hline \multicolumn{3}{|c|}{ Year of graduation } \\
\hline$>5$ years & 9 & $(21.4)$ \\
\hline \multicolumn{3}{|c|}{ Experience in years } \\
\hline$<5$ & 22 & $(52.4)$ \\
\hline$>5$ & 20 & $(47.6)$ \\
\hline \multicolumn{3}{|l|}{ Type of practicing } \\
\hline Sole proprietor & 2 & $(4.8)$ \\
\hline Partner proprietor & 5 & $(11.9)$ \\
\hline Manger & 5 & $(11.9)$ \\
\hline employee & 30 & $(71.4)$ \\
\hline \multicolumn{3}{|c|}{ Familiarity with MADRAC } \\
\hline Yes & 9 & $(21.4)$ \\
\hline No & 33 & $(78.6)$ \\
\hline \multicolumn{3}{|c|}{ Come cross with ADRS/12 months } \\
\hline Yes & 22 & $(52.4)$ \\
\hline No & 20 & $(47.6)$ \\
\hline \multicolumn{3}{|c|}{ ADRs reporting /12months } \\
\hline Never report & 28 & $(90.5)$ \\
\hline$>1$ report & 20 & $(9.5)$ \\
\hline \multicolumn{3}{|c|}{ Awareness of existence online reporting } \\
\hline Yes & 10 & $(23.8)$ \\
\hline No & 32 & $(76.2)$ \\
\hline \multicolumn{3}{|c|}{ Access to internet into working place } \\
\hline Yes & 31 & $(73.8)$ \\
\hline No & 11 & $(26.2)$ \\
\hline
\end{tabular}


Table 2. Comparison of Community Pharmacist Knowledge about Pharmacovigilance before and after the Educational Intervention, $(N=42)$

\begin{tabular}{|c|c|c|c|}
\hline Questions & $\begin{array}{c}\text { Correct Response before } \\
\text { Intervention } \\
n(\%)\end{array}$ & $\begin{array}{c}\text { Correct Response after } \\
\text { Intervention } \\
n(\%)\end{array}$ & $P$ Value \\
\hline $\begin{array}{l}\text { It is necessary to confirm that an } \\
\text { ADR is related to a particular drug } \\
\text { before reporting it. }\end{array}$ & $8(19.0)$ & $28(66.7)$ & $<0.001$ \\
\hline Adverse drug reaction definition. & $21(50.0)$ & $38(90.5)$ & $<0.001$ \\
\hline Pharmacovigilance definition. & $25(59.5)$ & $37(88.1)$ & 0.008 \\
\hline $\begin{array}{l}\text { Pharmacovigilance is considered } \\
\text { one of the aspects of Pharmacoepi- } \\
\text { demiology. }\end{array}$ & $29(69.0)$ & $41(97.6)$ & 0.002 \\
\hline $\begin{array}{l}\text { Type } B \text { reaction is unpredictable } \\
\text { and may be unrelated to the phar- } \\
\text { macology or dose of the drug. }\end{array}$ & $24(57.1)$ & $40(95.2)$ & $<0.001$ \\
\hline $\begin{array}{l}\text { Adverse Drug Reactions associated } \\
\text { with herbal products should not be } \\
\text { reported. }\end{array}$ & $7(16.7)$ & $23(54.8)$ & $0 . .001$ \\
\hline $\begin{array}{l}\text { Which of the following should be } \\
\text { responsible for pharmacovigilance } \\
\text { system in Malaysia? }\end{array}$ & $15(35.7)$ & $39(92.9)$ & $<0.001$ \\
\hline $\begin{array}{l}\text { The minimum information required } \\
\text { for the submission of an initial re- } \\
\text { port is... }\end{array}$ & $25(59.5)$ & $35(83.3)$ & 0.013 \\
\hline
\end{tabular}

quency, were slightly more than fifty percent of participants agreed that their knowledge in ADR limit their ability to detect and report of ADRs $(\mathrm{n}=32,55 \%),(\mathrm{N}=42, \mathrm{P}=0.004)$. Almost all of the community pharmacists $(\mathrm{n}=38,90 \%)$ indicated the need for information of how to report ADRs with regard to only one pharmacist (2\%) disagreed with the same statement post the educational program. Around $60 \%$ of the respondents $(n=27,64 \%)$ agree with the statement that "ADRs reporting in Malaysia needs to be simplified" comparing with about $48 \%(n=20)$ prior the program. Upon the completion of the educational program about $70 \%$ of the respondents $(\mathrm{n}=28)$ agreed that ADR reporting in Malaysia is not widely promoted by the relevant authorities unlike to the pre-education program $(\mathrm{n}=22,52 \%)$.

\section{DISCUSSION}

This is the first study of its kind which evaluates the impact of an interventional educational program on the community pharmacist's knowledge and perception towards pharmacovigilance and ADR reporting in Malaysia.

It is well accepted worldwide that health care professionals including community pharmacists have poor and inadequate knowledge regarding ADRs and pharmacovigilance activities [3-7].
Prior to the educational program, more than half of the surveyed pharmacists felt that they did not have any ideas on how to report ADRs and they felt that ADRs reporting in Malaysia were not widely promoted among community pharmacists by the relevant authorities. This feeling is not surprising since approximately more than two-third of the pharmacists admitted that they were not familiar with MADRAC, the body responsible for collecting information about ADRs occurring in Malaysia.

From these findings, it can be ascertained that underreporting of ADRs in Malaysia is due to insufficient publicity of the program by the competent authorities rather than the negative attitudes of the pharmacists themselves. The findings of the study showed the positive attitude of community pharmacists towards the Malaysian pharmacovigilance system. furthermore, all $(n=42,100 \%)$ the surveyed pharmacists felt that reporting ADRs is a part of their pharmaceutical duties, this finding is consistent with previous studies [8, 9]. The results of the study revealed a generally low level of awareness and knowledge about pharmacovigilance activities and ADR reporting among community pharmacist, which is in agreement with previous studies carried out elsewhere $[1,10,11]$.

Although, there are other ways to report ADRs beside the reporting form, almost two thirds $(n=32,76 \%)$ of the phar- 
Table 3. Community Pharmacist's Perception of Pharmacovigilance and ADR Reporting (n= 42)

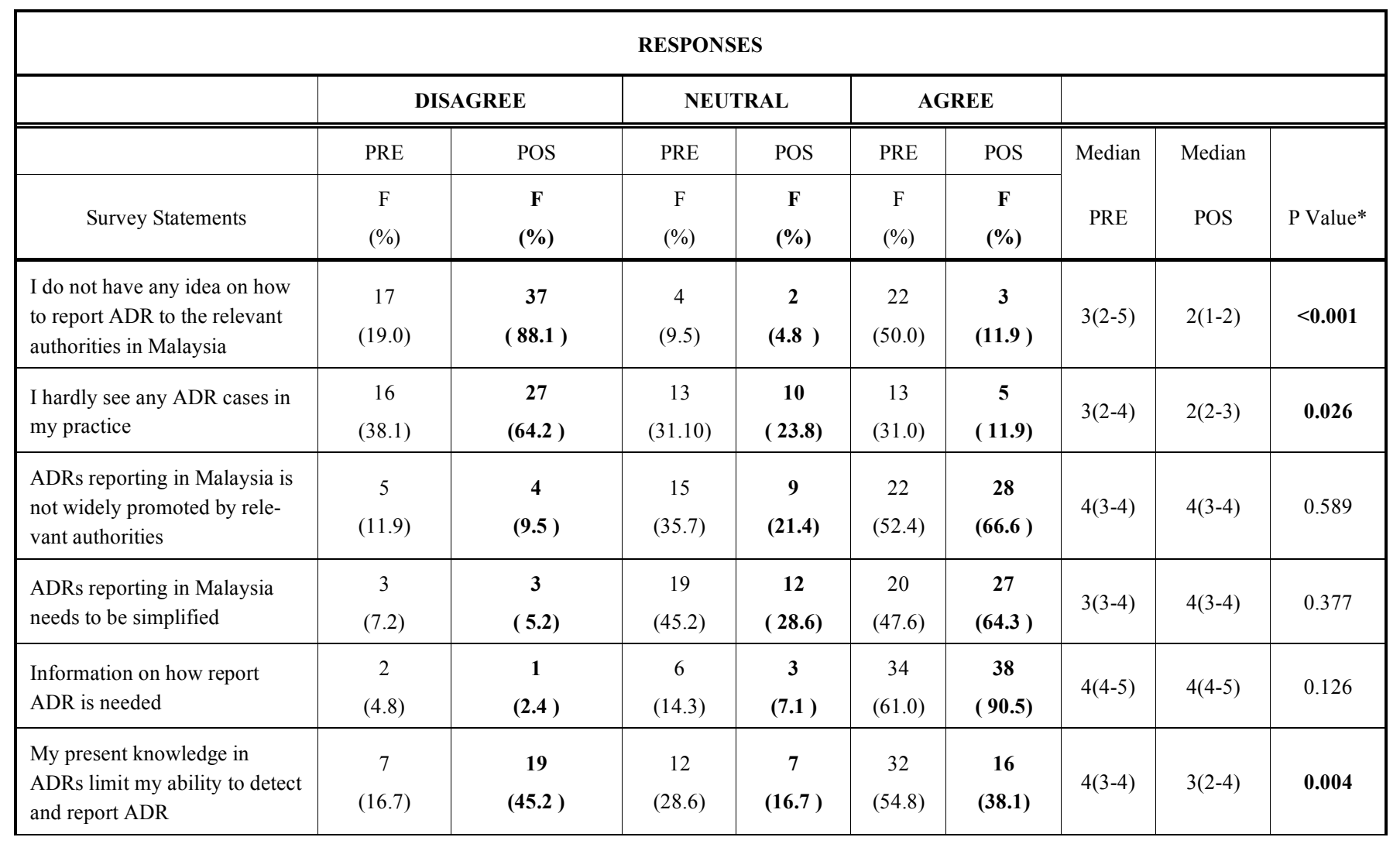

$\mathrm{F}=$ Frequency, $\mathrm{PRE}=$ Pre-test, $\mathrm{POS}=$ Post-test.

macists were unaware of the availability of online reporting and the existence of sending reports via the fax where the respective fax number was printed on the reporting form. These findings confirm the results of previous studies [4] where reporting through the online could facilitate ADRs reporting [10] and contribute to an increased involvement of CPs in pharmacovigilance activates. Obviously, that there was no statistical difference between the practicing of ADRs reporting and awareness of the existence online reporting $(P$ $=0.199)$, despite the vast majority of pharmacists $(74 \%)$ claimed that they possess access to the internet at their workplaces. These findings should encourage MADRAC and the other relevant authorities to publicize this facility amongst the community pharmacists to ensure a higher response rate from these professionals. Many reports have implicated that lack of knowledge amongst community pharmacist is a factor contributing to reporting in spontaneous ADRs reporting systems [12-14]. As such, increasing the delivery of information to community pharmacists about medicines and methods of detecting ADRs will lead to an improvement in their knowledge and increase a higher response rate of reporting ADRs [15]. The results of the present study indicate that the educational program is effective in improving the CPs knowledge of pharmacovigilance and changing the perception towards the ADRs reporting process, shown by the major change in the mean scores of knowledge upon the completion of the education program. Similar findings were reported by previous studies $[8,9,14$, $16]$.
The study results showed that the reporting rate among the surveyed pharmacist was very low $(9 \%)$. The reporting rate was found to be better amongst community pharmacist who participated in the Continuous Pharmaceutical Development (CPD) programs for more than 10 hours per year. Previous studies indicated that attending safety educational programs was a route for promoting positive attitudes and enhanced the perceptions of the health care professional towards drug safety monitoring concepts [17].

There was no statistical difference found between ADRs reporting practicing and other independent variables including age, gender, country of graduation, type of practice, participation in CPD and experience in years. This findings are consistent with previous studies $[18,19]$. Contrarily, Age , experience in years and participating in CPD had an impact on ADRs reporting as mentioned by other previous studies $[20,21]$. Previous studies also have shown that education and training in ADRs reporting increases the quality and the reporting rate [20,22]. In response to the question regarding the existence of the causality relationship between the drug and reporting of the suspected ADR $(n=14,33 \%)$ about onethird of surveyed pharmacists answered incorrectly, even it was not requested by MADRAC to prove that this relationship actually exists. There was a significant difference between the pre and post intervention program regarding this question $(\mathrm{P}<0.001)$. These findings are consistent with previous reports on CPs in other studies [13,22].

In the pre- assessment stage, only seven (17\%) pharmacists correctly answered to the question linked to knowledge 
about reporting of ADRs associated with herbal medicines. Responses to these questions clearly show that the majority of the community pharmacists were not aware of the guidelines from MADRAC concerning pharmacovigilance and ADR reporting processes. This weakness could be overcome by providing special practical training in this area. Approximately, all $(n=39,93 \%)$ of the pharmacists believe that MADRAC should be responsible for the pharmacovigilance system in Malaysia. Furthermore, almost all $(98 \%)$ of the participants agreed that pharmacovigilance is one of the aspects of Pharmacoepidemiology.

\section{LIMITATION}

Although, this study had some limitations such as; low participation rate, and a pre-post test for a single group without a longer period to follow up and determine whether the study's educational program is effective for promoting a positive change. Furthermore, the study was conducted only with community pharmacist of Penang and the findings may not to be extrapolated to the community pharmacists in the other states. However, the study generated data about the knowledge of and perception of community pharmacists towards pharmacovigilance activities and spontaneous reporting system in Malaysia, providing baseline data to improve the current ADRs reporting system.

The study findings may not reflect the perception of all the community pharmacists throughout the whole of Malaysia, where only those more likely to be influenced those who they were actually participated to the program. However, the findings should be interpreted within the confinements and limitations of the study and the environment where the study was carried out.

\section{CONCLUSION}

The educational program which was implemented in this study and focused on pharmacovigilance activities and ADRs reporting in Malaysia has brought about a positive change in the knowledge of and perception towards pharmacovigilance activities, compared with the base line results. It is obvious that the pharmacovigilance activities in Malaysia are not well promoted among community pharmacists by the relevant authorities.

\section{REFERENCES}

[1] MADRAC. Malaysian Adverse Drug Reactions Advisory Committee [home on internet]. Kuala Lumpur; 2002 [21 July 2008; cited 2007 March 6 ]. Available from: http://portal.bpfk.gov.my/index.cfm?menuid=24\&parentid $=16$.

[2] Rosebraugh C, Tsong Y, Zhou F, et al. Improving the quality of adverse drug reaction reporting by 4th-year medical students. Pharmacoepidemiol Drug Saf 2003; 12(2): 97-101.

[3] Graille V, Lapeyre-Mestre M, Montastruc JL. Drug vigilance: opinion survey among residents of a university hospital. Therapie 1994; 49(5): 451-4.
[4] Hasford J, Goettler M, Munter KH, Müller-Oerlinghausen B. Physicians' knowledge and attitudes regarding the spontaneous reporting system for adverse drug reactions. J Clin Epidemiol 2002; 55(9): 945-50.

[5] Figueiras A, Herdeiro M, Polonia J, Gestal-Otero J. An educational intervention to improve physician reporting of adverse drug reactions: a cluster-randomized controlled trial. JAMA 2006; 296(9): 1086.

[6] Lopez-Gonzalez E, Herdeiro M, Figueiras A. Determinants of under-reporting of adverse drug reactions: a systematic review. Drug Saf 2009; 32(1): 19-31.

[7] Sorokin R, Claves JL, Kane GC, Gottlieb JE. The near miss resident conference: understanding the barriers to confronting medical errors. Semin Med Pract 2002; 5(1): 17.

[8] Houghton J, Woods F, Davis S, Coulson R, Routledge P. Attitudes of community pharmacists and general practitioners in Wales. Pharm J 1999; 263(70-71): 788-91.

[9] Van Grootheest AC, Mes K, De Jong-Van Den Berg LTW. Attitudes of community pharmacists in the Netherlands towards adverse drug reaction reporting. Int J Pharm Pract 2002; 10(4): 26772.

[10] Bawazir S. Attitude of community pharmacists in Saudi Arabia towards adverse drug reaction reporting. Saudi Pharm J 2006; 14(1): 75-83.

[11] Cosentino M, Leoni O, Banfi F, Lecchini S, Frigo G. Attitudes to adverse drug reaction reporting by medical practitioners in a Northern Italian district. Pharmacol Res 1997; 35(2): 85-8.

[12] Granas AG, Buajordet M, Stenberg-Nilsen H, Harg P, Horn AM. Pharmacists' attitudes towards the reporting of suspected adverse drug reactions in Norway. Pharmacoepidemiol Drug Saf 2007; 16(4): 429-34.

[13] Green CF, Mottram DR, Raval D, Proudlove C, Randall C. Community pharmacists' attitude to adverse drug reaction reporting. Int J Pharm Pract 1999; 7: 92-9.

[14] Irujo M, Beitia G, Bes-Rastrollo M, et al. Factors that influence under-reporting of suspected adverse drug reactions among community pharmacists in a Spanish region. Drug Saf 2007; 30(11): 1073-82.

[15] Backstrom M, Mjorndal T, Dahlqvist R. Under-reporting of serious adverse drug reactions in Sweden. Pharmacoepidemiol Drug Saf 2004; 13(7): 483-7.

[16] Herdeiro M, Figueiras A, Polonia J, Gestal-Otero J. Influence of pharmacists attitudes on adverse drug reaction reporting: a casecontrol study in portugal. Drug Saf 2006; 29 4: 331-40.

[17] Coyle Y, Mercer S, Murphy-Cullen C, Schneider G, Hynan L. Effectiveness of a graduate medical education program for improving medical event reporting attitude and behavior. Br Med J 2005; 14(5): 383

[18] Ngorsuraches S, Li S. Thai pharmacist's understanding, attitudes, and perceived barriers related to providing pharmaceutical care Am J Health Syst Pharm 2006; 63(21): 2144.

[19] Enwere O, Fawole O. Adverse drug reactions reporting by physicians in Ibadan, Nigeria. Pharmacoepidemiol Drug Saf 2008; 17: 517-22.

[20] Sweis D, Wong ICK. A survey on factors that could affect adverse drug reaction reporting according to hospital pharmacists in great britain. Drug Saf 2000; 23(2): 165-72.

[21] Generali J, Danish M, Rosenbaum S. Knowledge of and attitudes about adverse drug reaction reporting among Rhode Island pharmacists. Ann Pharmacother 1995; 29(4): 365.

[22] Green CF, Mottram DR, Philip H. Rowe, Munir Pirmohamed. Attitudes and knowledge of hospital pharmacists to adverse drug reaction reporting. Br J Clin Pharmacol 2001; 51(1): 81-6. 